\title{
Estabilidade e concordância entre o cateter esofágico com micro-transdutor e o cateter de balão esofágico: estudo in vitro e in vivo
}

\author{
Renan Maloni Augusto', Carlos Roberto Ribeiro de Carvalho², \\ André Albuquerque ${ }^{2}$, Pedro Caruso ${ }^{2}$
}

Augusto RM, Carvalho CRR, Albuquerque A, CAruso P. Estabilidade e concordância entre o cateter esofágico com micro-transdutor e o cateter de balão esofágico: estudo in vitro e in vivo. Rev Med (São Paulo). 2015 jan.-mar.;94(1):66-7.

As medidas da força inspiratória e da pressão transdiafragmatica (Pdi) (Pdi= Pgástrica - Pesofágica) têm grande importância na prática clínica. Diversas doenças respiratórias e musculares afetam a Pdi, muitas vezes não sendo detectadadas através de medidas não invasivas. $\mathrm{O}$ presente estudo tem como objetivo avaliar a estabilidade, frequência de resposta e concordância entre o cateter com balão (BC) e o com microtransdutores (MTC) no estudo das pressões esofágicas, gástricas e Pdi.

\section{OBJETIVO}

Avaliar, in vitro e in vivo, a estabilidade, frequência de resposta e concordância entre o cateter com balão e com microtransdutores no estudo das pressões esofágicas, gástricas e Pdi.

\section{MÉTODOS}

In vitro: os cateteres tiveram sua resposta de freqüência e estabilidade avaliadas durante $6 \mathrm{~h}$ em uma coluna de água com pressões pré - estabelecidas.

In vivo: em 10 voluntários saudáveis, foi introduzido um BC e um MTC simultaneamente em uma narina e posicionados no mesmo nível do esôfago.

Foram analisadas, a estabilidade da Pesofagica, linha de base, $\Delta$ Pesofágica e Pesofágica durante a respiração normal e forçada. Para avaliação da concordância foram feitas medidas na posição sentada por três horas consecutivas.

Uma série de manobras respiratórias foram realizadas neste período: 1) respiração normal 2) cinco manobras de inspiração máxima através de uma narina com a outra ocluída (“sniff”) e 3) cinco manobras de Valsalva. O voluntário ficava sentado por 3 horas, sem movimentar-se. No início e fim do período eram feitas cinco manobras de “sniff” com duração máxima de 500ms. Ao fim da terceira hora o balão com látex era migrado para o estômago para ficar no mesmo local que o microtransdutor gástrico.

\section{RESULTADOS}

In vitro: A frequência de resposta do cateter com microtransdutores foi maior que a do cateter com balão de látex preenchido com ar $(261.7 \pm 26 \mathrm{~Hz}$ vs $114.2 \pm 33$ $\mathrm{Hz}, \mathrm{p}<0.001)$. Ao longo de seis horas e a partir de valores de 0 a $50 \mathrm{cmH} 2 \mathrm{O}$, o cateter com microtransdutor teve um desvio da pressão média de $-0.57 \pm 1,7$ (mínimo de -2.84 até máximo +2.80$)$.

In vivo: Analisados, 10 indivíduos sem comorbidades com idades entre 22 e 40 anos. O desvio da pressão esofágica foi maior no cateter de balão em comparação ao cateter de microtransdutor $(1.8 \pm 4.9 \mathrm{cmH} 2 \mathrm{O}$ vs $-3.1 \pm 6.1$ $\mathrm{cmH} 2 \mathrm{O}, \mathrm{p}<0.001)$.

$2^{\circ}$ lugar Prêmio Painéis - Área Clínica no 33 COMU - Congresso Médico Universitário da FMUSP, SP, 31 de out. a 02 de nov. de 2014. 1. Acadêmico de Medicina da Faculdade de Medicina da Universidade de São Paulo.

2. Orientadores, Faculdade de Medicina da Universidade de São Paulo. 
Os valores extremos de desvio foram de -10.4 to $+16.7 \mathrm{cmH} 2 \mathrm{O}$ para o cateter de microtransdutor e de -23.2 to $+9.2 \mathrm{cmH} 2 \mathrm{O}$ para o cateter de balão de látex.

O coeficiente de variação do cateter de balão foi maior que o do cateter de microtransdutor (28.9\% vc $9.9 \%)$.

\section{CONCLUSÕES}

Concluímos que a perda basal de pressão é menor no cateter com microtransdutor, assim como seu coeficiente de variação. A concordância entre os métodos foi baixa, portanto os métodos não podem ser considerados como equivalentes. 